\title{
AUTORIA INDÍGENA EM QUINZE ANOS DE CARTAS
}

\section{INDIGENOUS AUTHORSHIP IN FIFTEEN YEARS OF LETTERS}

\author{
Suzane Lima Costa* \\ Rafael Xucuru Kariri**
}

\section{RESUMO}

São muitas as pesquisas que analisam cartas sobre os povos indígenas para uma compreensão crítica da história política e literária do Brasil. Nessas análises, as epístolas são tratadas como valorosos arquivos dos processos de criação dos seus autores, testemunhos de notórias situações identitárias e políticas e/ou documentos históricos/biográficos fundamentais para entendermos a nossa história. Todavia, há uma lacuna significativa nessas pesquisas e abordagens quando o indígena se torna o remetente das cartas, o autor desse tipo de texto, ou seja, quando a biografia, o testemunho ou o documento histórico foi produzido pelo próprio índio. Em 2013, elaboramos o projeto As cartas dos povos indígenas ao Brasil, tanto para discutir essa lacuna, quanto para criarmos o primeiro arquivo virtual e físico dessas correspondências - fundamentais hoje para apresentação de uma outra versão do Brasil, narrada e criada pela autoria dos povos indígenas. Neste artigo, analisaremos as especificidades de algumas dessas correspondências, discutindo a carta como suporte utilizado pelos indígenas para uma conversação com o Brasil, o próprio Brasil enquanto destinatário dessas correspondências e os modos de construção da autoria coletiva entre os indígenas, ensejando, assim, uma política linguística/identitária muito própria.

Palavras-chave: cartas; povos indígenas; autoria.

\section{ABSTRACT}

There are many studies that analyze letters about indigenous peoples for a critical understanding of Brazil's political and literary history. In these analyzes, the epistles are treated as valuable archives for the creative processes of their authors, testimonies of notorious identity and political situations or historical/biographical documents foundational to understand our history. However, there is a significant gap in these researches and approaches when the indigenous becomes the sender of the letters, the author of this type of text, that is, when the biography, testimony or historical document was produced by the indigenous himself. In 2013, we prepared the project The Letters of Indigenous Peoples to Brazil to discuss this gap and to create the first virtual and physical archive of these correspondences - fundamental for the presentation of another view from Brazil, narrated and created by authorship of indigenous peoples. In this article we will analyze the specificities of some of these correspondences, discussing the letter as a support used by the natives for a conversation with Brazil, Brazil itself as the recipient of these correspondences and the ways of constructing collective authorship among the natives, which envisages a particular language policy and identity politics.

Keywords: letters; Indigenous peoples; authorship.

\footnotetext{
* Universidade Federal da Bahia UFBA, Salvador (BA), Brasil. suzanelimacosta@gmail.com

** Ministério da Educação / Universidade Federal da Bahia UFBA, Salvador (BA), Brasil. rafael. silva_19@hotmail.com
} 
Há mais de uma década os povos indígenas escrevem cartas ao Brasil. Cartas sobre seus mortos, suas questões políticas e identitárias, suas terras, seus inimigos, cartas sobre suas vidas (COSTA, 2018). Temos o registro hoje de 664 cartas assinadas coletiva e individualmente por indígenas, produzidas nos últimos quinze anos e disponibilizadas em sites de organizações não-governamentais e em redes sociais, sem contar as cartas presentes em acervos da FUNAI e demais arquivos históricos físicos. O outro dessas cartas é o Brasil, destinatário das correspondências. Os indígenas endereçam seus escritos aos presidentes da república, ao poder judiciário ou, simplesmente, aos brasileiros. O Brasil é o vocativo presente na vontade de conversação dos indígenas, mas 'ausente' na resposta, no possível pacto de interlocução que, por vezes, a escrita epistolar exige. Mas por que escrever cartas como alternativa para uma conversação com o Brasil? Qual o teor dos diálogos epistolares dos indígenas? O que é fazer do Brasil o destinatário dessas cartas?

Essas questões fazem parte de um conjunto maior de reflexões que desenvolvemos desde o início de 2012, com a elaboração do projeto de pesquisa As cartas dos Povos indígenas ao Brasil. No final de 2013, passamos a pesquisar as composições desse tipo de escrita e elaboramos o subprojeto de pesquisa intitulado Autobiografias indígenas em trinta anos de cartas ${ }^{1}$ com o intuito de colocar em circulação essas correspondências e de discutir a questão da autoria e da formação do espaço autobiográfico indígena. Para nossa surpresa, encontramos um número muito expressivo de cartas escritas anualmente pelos indígenas, em sua maioria em língua portuguesa, e espalhadas em sites de organizações não governamentais e em redes sociais durante o período de 2000-2015. Percebemos que essas cartas tinham um agenciamento temporal particular, porque acompanhavam o modo como os indígenas compreendiam e respondiam aos imperativos jurídicos e históricos que o Estado brasileiro imprimia em seus corpos. Sem contar que nelas havia também uma constante defesa da própria identidade indígena e do território, o que reverberou em escritos que pediam o reconhecimento de uma cidadania diferenciada para os povos.

Além das questões, levantadas durante a primeira coleta das cartas, também nos chamaram atenção especial a autoria coletiva dos indígenas, registrada nas assinaturas e composições de mais de trezentas cartas. Nessas cartas, vemos em

1. Projeto financiado pelo $\mathrm{CNPq}$ que teve como objetivo central montar o arquivo das cartas produzidas pelos povos indígenas e que hoje circulam com ampla repercussão nas redes sociais e em portais de notícias dentro e fora do Brasil, bem como das cartas que, fora do espaço virtual, foram encaminhadas por líderes indígenas às organizações internacionais e ao Governo Federal do Brasil, desde a promulgação dos direitos indígenas na Constituição de 1988 até 2015. 
destaque, mudando apenas o nome de cada grupo étnico, a assinatura coletiva do povo e no corpo do texto a defesa de que o povo indígena é o verdadeiro autor da escrita. O que coloca em evidência não só o processo de criação desses textos, como também as práxis colaborativas produzidas entre os próprios indígenas para sua confecção. Albert Braz, no seu artigo «Collaborative Authorship and Indigenous Literatures», discute a questão da colaboração autoral na literatura de autoria indígena, enfatizando que uma das características que define essa literatura é a incidência da indeterminação de um único escritor (BRAZ, 2011). Muito antes do Braz, no final da década de 1980, no livro For those who after: a study of native american autobiography (1989), Arnold Krupat (1989) discute a mesma questão, analisando quem estaria autorizado a anexar um único nome de autor à voz indígena, que sempre teve no anonimato, e na não condição de propriedade, a base e fundamento da sua literatura.

Questões mais recentes, produzidas sobre a autoria indígena, como as elaboradas por Jane Stanford (2016), em seu livro Colonial Literature and the Native Author: Indigeneity and Empire, alargam a discussão apresentada por Krupat (1989) ao perguntar o que acontece quando o romantizado assunto da literatura colonial se torna autor da escrita que sempre foi considerada como própria da linguagem do império. Stanford questiona se um novo tipo de escrita é produzido ou se o autor indígena repete os mesmos modelos do colonizador.

Para lidar com essas questões tão recorrentes durante o processo da pesquisa, decidimos organizar as correspondências produzidas pelos indígenas da seguinte forma: 1) As cartas aos 500 anos (correspondências que compreendem o marco dos 500 anos do Brasil e que foram destinadas ao Presidente Fernando Henrique Cardoso); 2) As cartas para os presidentes Luiz Inácio Lula da Silva e Dilma Rousseff (correspondências que marcam a entrada do Partido dos Trabalhadores na Presidência do Brasil); 3) As cartas aos mortos e as cartas de repúdio (correspondências que denunciam os crimes e suicídios de indígenas nos processos de retomada das suas terras) ; 4) As cartas das mulheres indígenas (correspondências nas quais as mulheres repudiam a ação do Estado e dos fazendeiros); 5) As cartas de reconhecimento ou as cartas da terra (correspondências que comunicam a autodemarcação dos territórios indígenas). Neste artigo, analisaremos as especificidades de algumas dessas correspondências, discutindo o porquê do uso da carta enquanto suporte para a conversação com o Brasil, o próprio Brasil enquanto destinatário dessas cartas e os modos de construção da autoria coletiva entre os indígenas. 


\section{POR QUE ESCREVER CARTAS AO BRASIL?}

Foi Barthes quem disse que uma carta é um encontro de saberes entre dois, um saber que atua simultaneamente em quem escreve e em quem lê (BARTHES, 2008). Para Foucault (2004), uma carta é o próprio exercício da alteridade, uma vez que quem as escreve se faz presente àquele com quem deseja falar. Já para Lejeune (2008), por definição, uma carta é uma partilha que envolve várias pessoas e que possui vários aspectos: "é um objeto (que se troca), um ato (que pode ser publicado)" (LEJEUNE, 2008, p. 252), ou seja, um modo de conversar de perto ainda que os sujeitos da conversação estejam em temporalidades distintas. Nesse processo de produção de partilhas, os dois das cartas dos indígenas são um coletivo de atores. Quem remete assina no plural - o povo - e quem recebe a carta o faz por um coletivo - o Brasil. Os dois coletivos desse modo de conversar possuem também seus jeitos de escrever e de se fazer ausente/presente na prática dialógica.

Essa dialogia, de algum modo, sempre esteve presente na história do Brasil, das correspondências Tupi dos Camarões, no século XVII, à carta de Sônia Guajajara lançando sua pré-candidatura à Presidência da República no século XXI. Esses escritos resultam de complexos processos de escolarização pelos quais passaram alguns grupos étnicos indígenas ao longo da nossa história - processos que, dada as devidas diferenças de temporalidades, hoje já fazem parte da organização política dos próprios indígenas. As cartas escritas por esses povos são extensão de alguns desses modos de organização, por isso, para apresentar a autoria coletiva dos indígenas é fundamental entender os modos de criação escrita desses autores em seus grupos, coletivos e associações.

Parte dessas organizações iniciaram com as assembleias indígenas na década de 1970, apoiada por parceiros do movimento indígena². Nesses encontros participavam povos de diferentes regiões do país que se reuniam para discutir a situação de seus territórios tradicionais e a política de integração forçada à sociedade não-indígena, promovida pelo Governo Militar. ${ }^{3}$ Após a Constituição de 1988, esses encontros passaram a ser organizados em âmbito local, regional e nacional por lideranças, professores, mulheres, anciões e escritores indígenas, reunidos para

2. Parceria com antropólogos, indigenistas, linguísticas e demais membros de organizações da sociedade civil. Vale destacar a parceria do Conselho Indigenista Missionário (CIMI), ligado à Igreja Católica.

3. O projeto oficial previa que os indígenas, enquanto grupo evolutivamente inferior ao modelo ideal de civilizado, deveriam 'evoluir' para a condição de brasileiro por meio da integração forçada, utilizando-se instrumentos como a imposição do uso da língua portuguesa, a expulsão dos territórios tradicionais e a inserção no mercado de trabalho. 
tratar de situações repetidamente vividas pelas comunidades: a luta pela terra, o assassinato de lideranças e a denúncia de abusos e violências outras sofridas.

Os resultados dessas conversações encontraram no objeto/ato carta seu formato ideal de difusão e de partilha. Em 2014, acompanhamos algumas dessas reuniões e registramos os modos como, da traduzibilidade da oralidade para a escrita, os diálogos, decisões e discussões passaram a ser pactuados e produzidos coletivamente por membros da comunidade. Ao final de cada reunião coletiva uma carta era escrita e encaminhada ao destinatário, coletivizado ou singularizado como 'o Brasil'. Nesse momento, a carta-objeto se tornava carta-ato performático de presença e agência diante do outro - o receptor da correspondência - e diante do próprio remetente que a produziu.

Em geral, as correspondências indígenas são produzidas em língua portuguesa e contém um resumo da discussão feita pelo grupo, com uma introdução sobre o local, uma descrição dos povos presentes no momento da escrita, o objetivo e as questões levantadas para a conversa. Por vezes, essa sequência é entrecortada por histórias pessoais, por situações vividas com outros atores indígenas e nãoindígenas e por imagens míticas e metáforas para explicar seus sentimentos ao interlocutor. Percebemos que cada povo elabora um modo diferente de agenciar essa traduzibilidade, sendo um dos mais recorrentes a escolha por um ou mais tradutores, geralmente indígenas mais jovens, que possuíam os letramentos necessários para reproduzir por escrito as demandas orais apresentadas pelo grupo.

Os contornos dessa traduzibilidade exigem uma compreensão sobre o papel do tradutor no processo de montagem das cartas coletivas. Isso porque o tradutor é também um editor do texto, mas não um editor com plena liberdade para sua montagem, uma vez que o seu trabalho está sob a avaliação dos demais indígenas presentes na roda de discussão. Assim, palavras, expressões, imagens e metáforas passam por um processo contínuo de negociação durante a transcrição, além do fato de que, ao final da escrita, é necessário que o tradutor apresente oralmente o resultado da carta para a escuta e aceitação dos demais indígenas. Por outro lado, é o tradutor quem agencia o processo de produção performática do texto, ele é o performer do ato de escrever. Os indígenas não escolhem simplesmente o índio que possui escolaridade ou que domina os regramentos da escrita, além desses atributos, é necessário ter o corpo que transita entre os saberes de si, da sua aldeia, da sua cultura e os saberes do outro com quem se dispõe a conversar.

Ao definir a noção de tradutor, quando se refere às tradições orais indígenas, Lynn Mario de Souza (2006) traça uma ligeira diferenciação entre os atos de escrever e transcrever, observando que uma série de elementos da performatividade oral 
não aparecem nas formas escritas de algumas práticas de transcrição de narrativas indígenas. Desse modo, continua o autor, "a performatividade da tradição oral (...) se perde totalmente, fazendo com que aquilo que nasceu como processo oral ou performance se torne um mero produto escrito." (SOUZA, 2006, p. 204). Souza se refere aqui às traduções das práticas orais de culturas sem escrita, nas quais os contadores de histórias escolhem algumas práticas performáticas para apresentar à uma plateia a narrativa. "Assim, os autores que dizem que estão simplesmente escrevendo (registrando no papel) narrativas indígenas tal qual foram contadas, na verdade estão deixando para fora do papel toda a complexidade e dinâmica do processo performativo de narrar oralmente." (SOUZA, 2006, p. 203)

Diferentemente da prática do tradutor dessas literaturas orais, o tradutor das cartas é um 'transcriador' do processo de escrita; um transcriador plural, não só porque não está sozinho no ato da escrita, mas porque precisa estar presente na escuta ativa das outras vozes que ditam e interagem oralmente com o texto no mesmo momento da sua construção. $\mathrm{O}$ transcriador não está alheio às demandas da comunidade, pelo contrário, partilha do mesmo desejo coletivo do grupo, é sua própria extensão, e por isso traduz os artifícios da performatividade oral do seu pertencimento para a carta. Nessa atuação, a autoria está nas intersecções da oralidade para a escritura, na possível condição da sua não separação. Quiçá por isso é possível dizer que os indígenas que escrevem cartas performatizam essa escrita o tempo inteiro, justamente para garantir a validade autoral do texto.

Selecionamos dois trechos de epístolas que exemplificam esse tipo de performance e que ilustram bem como uma carta pode ser um ato coletivo de resistência. O primeiro deles foi retirado da carta escrita em 2014 pelos Munduruku da Aldeia Sawré Muybu e encaminhada aos brasileiros para dizer porque decidiram produzir eles próprios os processos de demarcação das suas terras:

Aldeia Sawré Muybu - Itaituba/PA, 17 de novembro de 2014.

Brasil,

Nossos antigos nos contavam que o tamanduá é tranquilo e quieto, fica no cantinho dele não mexe com ninguém, mas quando se sente ameaçado mata com um abraço e suas unhas.

Nós somos assim. Quietos, tranquilos, igual o tamanduá. É o governo que está tirando nosso sossego, é o governo que está mexendo com nossa mãe terra nossa esposa (MUNDURUKU, 2014).

Ser o tamanduá é colocar a si mesmo como partícipe da representação que se está apresentando, não para afirmar uma representação de si - uma identidade 
Munduruku - como condição valorativa da sua própria autoria, mas para produzir uma re-apresentação, que põe em xeque o seu próprio corpo, porque aposta em tudo que existe como representável. E se assim o faz, a performance ensaia também uma crítica à noção de representação e de sujeito da escrita.

Uma outra mostra disso está na carta escrita em 31 de janeiro de 2011 pelos Kaiowá para congratular a Presidenta Dilma pela sua eleição e pedir, mais uma vez, a devolução do território ancestral Kaiowá, seu Tekohá:

Dourados, 31 de janeiro de 2011.

Presidente Dilma

Que bom que a senhora assumiu a presidência do Brasil. É a primeira mãe que assume essa responsabilidade e poder. Mas nós Guarani Kaiowá queremos lembrar que para nós a primeira mãe é a mãe terra, da qual fazemos parte e que nos sustentou há milhares de anos. Presidenta Dilma, roubaram nossa mãe. A maltrataram, sangraram suas veias, rasgaram sua pele, quebraram seus ossos. (...) Presidente Dilma, a questão das nossas terras já era para ter sido resolvida há décadas. Mas todos os governos lavaram as mãos e foram deixando a situação se agravar. (KAIOWA, 2011)

Aqui é o próprio destinatário quem está exposto a uma extensão/distinção radical de si - não a uma representação. $\mathrm{O}$ jogo entre ser mãe, ser terra e ser o próprio Brasil é que constrói o paradoxal sentido dessa dialogia constituída para dizer da ausência do destinatário, a medida em que o torna presente na temporalidade e no contexto da narrativa. Quem escreve performatiza sua própria condição de remetente não para garantir a possibilidade do encontro, mas para dizer, ainda que seja como uma alternativa final à vontade de conversa, que quem está ali é muito mais a pessoa do que o personagem da escrita. Com uma pequena correção: a pessoa não tem nome próprio - ela é um povo, uma aldeia, uma comunidade.

A autoria coletiva das cartas apresenta um modo também de entendermos que "somos todos vários quando escrevemos, mesmo sozinhos, mesmo nossa própria vida" (LEJEUNE, 2008, p. 118). O princípio da autoria entre os indígenas permite essas práticas colaborativas e, como o próprio Lejeune defendeu, permite não para legitimar a ideia acerca de um eu dividido, mas para dizer "da articulação das fases de um trabalho de escrita que pressupõe atitudes diferentes e vincula quem escreve tanto ao campo dos textos já escritos, quanto à demanda que escolheu satisfazer" (LEJEUNE, 2008, p. 118). 


\section{O BRASIL DESTINATÁRIO/INTERLOCUTOR DOS INDÍGENAS}

Parte significativa das cartas coletivas escritas por indígenas foram elaboradas nos encontros supracitados como manifestos autorais do povo para exigir do Brasil e dos brasileiros ciência e respostas às situações de abandono, violência e morte sofridas em suas aldeias. $\mathrm{O}$ constante endereçamento de cartas ao Brasil direcionou nossa pesquisa à seleção desse destinatário como primeiro princípio metodológico para a criação do arquivo virtual das cartas dos povos indígenas. Uma carta emblemática dessa seleção foi escrita pelos povos Mehinaku e Xavante, em 22 de abril de 2000, e endereçada aos Presidentes do Brasil e de Portugal, respectivamente, Fernando Henrique Cardoso e Jorge Sampaio:

Estamos aqui com toda verdade de nossa tradição.

Sem rancor, sem raiva. Mas, também não estamos comemorando nada.

Esta não é nossa comemoração.

Apesar de toda distância e dificuldade, viemos porque temos que falar com vocês.

Estamos aqui para fazer um novo contato.

Nossos antepassados, nossos avós aceitavam os "presentes" que vocês deixavam para enfeitiçar nosso povo e pensavam que era uma atitude de amizade verdadeira. Acreditavam que aceitando os presentes vocês iam nos respeitar, que estaríamos protegidos. Mas essa história se repete. As frentes de atração continuam usando essa mesma tática para atrair e iludir nossos parentes que nem sabem que o Brasil existe (XAVANTE; MEHINAKU, 2000)

Escrever para um Brasil que nem se sabe que existe para fazer um novo contato é apostar na carta não como um texto que obriga à correspondência, à reciprocidade, mas como um ato que mobiliza quem escreve em direção ao seu próprio cuidado. Isso porque a troca em si não é a ação principal que define o objetivo da carta para os indígenas, mas sim a necessidade de criar sentidos para sua relação com o seu interlocutor, mesmo diante da ausência de respostas. Dessa necessidade nos fala Liz Stanley ao definir a 'intenção epistolar' como característica essencial ao gênero carta, porque diz da "intenção de comunicar [...] à outra pessoa que não 'está lá', não está presente porque foi removida do tempo/espaço do escritor", mesmo que o faça "com a esperança ou expectativa de resposta" (STANLEY, 2015, p. 03 , tradução nossa). ${ }^{4}$

4. The intention to communicate [...] to another person who is 'not there' because removed in time/ space from the writer, and doing so with the hope or expectation of a response. 
Nessa ordem da escrita da carta como autocuidado e/ou vontade de dizer, uma correspondência pode ser endereçada a toda uma sociedade, povo ou comunidade, que também podem ser os remetentes de uma carta, ainda que para isso, respectivamente, se personalize o destinatário no nome do presidente da república, ou que se performatize o lugar do tradutor no nome do Povo. Por outro lado, ainda que um contínuo de reciprocidade exista mesmo em quem só tenha a intenção de comunicar, as cartas não deixam de ser práticas sociais que envolvem um tipo específico de encontro entre quem as escreve e quem as lê.

É o que observamos em nossa segunda seleção de cartas para o Brasil enviadas pelos Yanomami, Terena e outros povos indígenas aos presidentes Luiz Inácio Lula da Silva e Dilma Rousseff:

Watoriki, 08 de Janeiro de 2003.

Senhor Presidente:

Nós, Yanomami, estamos contentes, pois o senhor foi eleito presidente. O senhor prometeu melhorar o Brasil, por isso nós, Yanomami, estamos também nessa expectativa.

$[\ldots]$

Apesar de não ter nos enviado uma carta, queremos que fique ciente de nosso pensamento e nos apoie. Quando o senhor era candidato lhe enviamos um primeiro documento e não recebemos resposta ${ }^{5}$, esperamos que agora possa nos responder. (YANOMAMI, 2003).

Porto Alegre RS, 28 de janeiro de 2005.

Lula, a omissão vence a esperança!

Nós, Povos Indígenas do Brasil, participantes do Puxirum de Artes e Saberes Indígenas no V Fórum Social Mundial ${ }^{6}$ levantamos nossa voz para denunciar a continuidade do processo de colonização forçada que vem se reproduzindo nos dias atuais em nosso país. Estamos cansados de enviar documentos e bater nas portas dos gabinetes governamentais sem que haja respostas para a solução dos graves problemas que enfrentamos (POVOS INDÍGENAS DO BRASIL, 2005).

5. Carta datada de 16 de setembro de 2002: "Muito bem, agora nós, Yanomami, queremos ouvir as palavras de vocês. Vocês, líderes dos Brancos, escrevam uma carta, para nós líderes Yanomami, porque queremos também ouvir as suas palavras. Esperamos a sua carta aqui [na floresta]" (YANOMAMI, 2002).

6. O Fórum Social Mundial é um evento altermundialista organizado por movimentos sociais, com o principal objetivo de elaborar alternativas para uma transformação social global, cujo lema é Um outro mundo é possivel. O V Fórum foi organizado na cidade de Porto Alegre, Rio Grande do Sul. 
Exma. Sra. Mãe da Nação Brasileira - Dilma Rousseff,

Nós mães Indígenas Terenas de Mato Grosso do Sul, parentes do indígena assassinado Oziel Gabriel ${ }^{7}$ e mães dos demais Guerreiros Terenas, que neste momento histórico arriscam suas vidas nas retomadas de nossas terras, sentindo-se impotentes diante da gravidade da situação e temendo novas mortes entre nossos filhos, pobres e ricos, índios e nãos índios; porém, estamos assistindo nossos filhos serem massacrados pelas forças públicas comandados por essa mesma mãe da nação. Ao invés de nos proteger ela fecha os olhos para não enxergar nosso sofrimento e tapa os ouvidos para não escutar nossos gritos de dor e lamentos, se negando a resolver a questão e sequer se solidariza com a causa indígena ou se sensibiliza com a matança do nosso povo em nosso Estado. Que mãe é essa que aconchega os fortes e assassina os fracos? (MÃES TERENA, 2013).

Se considerarmos que os Yanomami chegam a solicitar explicitamente a continuidade do diálogo ou que os diferentes povos reunidos no Fórum Social Mundial continuam a escrever cartas sem respostas de seus interlocutores ou ainda que as mães Terenas narram os assassinatos de seus filhos e apelam pela conversa, poderíamos dizer que a noção de correspondência entre os indígenas ultrapassa a própria ideia de interlocução que construímos ao longo da escrita deste artigo. O Brasil-destinatário, representado pelos seus Presidentes, está ausente nas respostas e na resolução dos problemas apresentados, mas é ele o ator de uma reciprocidade sem resposta, porque a ausência de respostas não interfere no processo de continuar a conversação, uma vez que a intenção epistolar estará sempre presente. Essa ideia está na base da argumentação de Sarah Poustie ao defender que a carta não perde suas características quando não expressa intenção de troca ou possibilidade de reciprocidade. Para a autora, o paradoxo aqui é que, ao se referirem às cartas não enviadas em cartas enviadas, elas são, com efeito, "enviadas" e a reciprocidade, a troca ou a interlocução ocorrem de maneira relativa" (POUSTIE, 2010, p. 27, tradução nossa). ${ }^{8}$

Ora, a falta de resposta acaba por ser um estimulador da escrita de mais cartas, como deixam claro os povos indígenas reunidos no Fórum Social Mundial ao afirmarem que a falta de resolução para as problemáticas apresentadas nas correspondências com o Governo se tornou a motivação para a escrita de uma carta que denuncia os processos de colonização. Assim, a ausência do Brasil-destinatário

7. Oziel Gabriel, 36 anos, morto a tiros durante ação de reintegração de posse de área da fazenda Buriti, em Sidrolândia, no estado de Mato Grosso do Sul.

8. No original: "The paradox here is that, by referring to unsent letters in sent letters, they are in effect sent and reciprocity, exchange and communication concerning them follows." 
não significa ausência das características de uma carta ou desestímulo à escrita, ao contrário, os indígenas exploram o silêncio do destinatário como metáfora da sua relação com a sociedade brasileira, o que torna as cartas indígenas promotoras de novas configurações para o gênero epistolar.

\section{EPÍSTOLAS INDÍGENAS E OS CONTORNOS DE UMA PESQUISA}

A escrita epistolar sempre esteve presente na história da literatura brasileira. Das primeiras escrituras coloniais aos modos contemporâneos de se escreverem cartas, as conversações entre remetente e destinatário nos colocam diante de pactos biográficos e de paisagens intelectuais e temporais da nossa própria história. No Brasil, são muitas as pesquisas que analisam cartas produzidas sobre os povos indígenas para uma compreensão crítica da nossa história política e literária. Nessas análises, as epístolas são tratadas como valorosos arquivos dos processos de criação dos seus autores, testemunhos de notórias situações políticas e/ou documentos históricos/ biográficos fundamentais para compreendermos a nossa história. Todavia, há uma lacuna significativa nessas pesquisas e abordagens quando o indígena se torna o remetente das cartas, o autor desse tipo de texto, ou seja, quando a biografia, o testemunho ou o documento histórico foi produzido pelo próprio índio. Há, inclusive, a dúvida sobre a autoria do texto e a imediata associação à ideia de que não seria possível aos indígenas no Brasil escrever cartas (ou qualquer outro tipo de texto), principalmente quando essa escrita está diretamente ligada ao 'Brasil' antes da Nova República.

No entanto, esse gênero de escrita perfila entre os indígenas desde o século XVII com a introdução das práticas de escrita alfabética pela colonização europeia. Algumas dessas cartas foram traduzidas em 1912 pelo historiador Pedro Souto Maior (MAIOR, 1913), outras estão ainda sem tradução e disponíveis nos Arquivos da Real Biblioteca (Koninklijke Bibliotheek) da Holanda, em Haia (Nationale Bibliotheek van Nederland), como é o caso das cartas dos indígenas Antonio Paraopeba, Pedro Poty e Felipe Camarão. Essas correspondências encontram, salvaguardando a devida distância temporal, na atualidade das correspondências produzidas por Marcos Terena, Gabriel Gentil, Azilene Kaingang e Sônia Guajajara, o Brasil em outra versão da sua própria história.

Na nova etapa do projeto As cartas dos Povos indígenas ao Brasil, decidimos investir na seleção e análise das cartas individuais, escritas em diferentes períodos da história do Brasil para analisar os modos como diferentes líderes indígenas, ao biografarem suas próprias vidas, narram uma outra história do Brasil. Para tanto, 
decidimos pesquisar as cartas dos indígenas em três importantes períodos da nossa história literária e política: 1630-1680 (antes do Brasil), 1888-1930 (na nação Brasil) e entre 2015-2018 (no presente Brasil).

Com esse novo recorte, pretendemos criar um arquivo dessas cartas em uma plataforma digital - espaço para outros estudos sobre escrita epistolar no Brasil, bem como para a difusão de uma outra versão do Brasil narrada e criada pela autoria dos povos indígenas. Essa plataforma contribuirá para difusão de um material literário e histórico inédito, que poderá ser livremente acessado por professores de escolas públicas, pesquisadores em universidades, linguistas e historiadores pertencentes a instituições nacionais e internacionais de pesquisa e ensino.

\section{REFERÊNCIAS}

BARTHES, R. (2008). O prazer do texto. 4. ed. Tradução J. Guinsburgl. São Paulo: Perspectiva.

BRAZ, A. (2011). Collaborative Authorship and Indigenous Literatures. CLCWeb: Comparative Literature and Culture. West Lafayette, v.13, n.2, p. 2-10.

COSTA, S. L. As cartas dos Povos Indígenas ao Brasil. Memoria Americana: Caudernos de etnobistoria. Buenos Aires, UBA, 2018, Vol. 26, n.1, p. 94-104.

FOUCAULT, M. (2004). Escrita de si. In: Ética, sexualidade, política. Tradução Elisa Monteiro, Inês Autran Dourado Barbosa. Rio de janeiro: Forense Universitária.

KAIOWA. (2011). Carta do Povo Kaiowá e Guarani à Dilma Vana Rousseff, Presidenta do Brasil entre os anos de 2011 a 2016. Disponível em: < http://www.ihu.unisinos.br/noticias/40380-cartado-povo-kaiowa-e-guarani-a-Presidenta-dilma-rousseff- $>$. Acesso em: 7 set. 2016.

KRUPAT, A. (1989). For Those Who Come After: a study of native american autobiography, University of California Press.

LEJEUNE, P. (2008). O pacto autobiográfico: de Rousseau à internet. Trad. Jovita G. Noronha e Maria Inês C. Guedes. 1. ed. Belo Horizonte: UFMG, 2008.

MÃES TERENA. (2013). Carta das mães Terena à mãe da nação Dilma Roussef. Disponível em: $<$ http://odescortinardaamazonia.blogspot.com.br/2013/06/carta-das-maes-terenade-mato-grosso-do.html >. Acesso em: 9 set. 2016.

MAIOR, P. S. (1913). Fastos Pernambucanos. Rio de Janeiro: Imprensa Nacional. 
MUNDURUKU. (2014). I carta da autodemarcação do território Daje Kapap Eypi. Disponível em: $<$ https://autodemarcacaonotapajos.wordpress.com/category/cartas/page/2/> Acesso em: 03 out. 2016.

POUSTIE, S. (2010). Re-Theorising Letters and 'Letterness', Olive Scbreiner Letters Project Working Papers on Letters, Letterness \& Epistolary Networks, v. 1, p. 1-50.

POVOS INDÍGENAS DO BRASIL. (2005). Lula, a omissão vence a esperança! Disponível em: $\quad<$ http://www. cimi.org.br/site/pt-br/? system = news\&action = read\&id $=969>$. Acesso em: 28 ago. 2016.

SOUZA, L. M. T. M. (2006). Uma outra história, a escrita indígena no Brasil. In: RICARDO, B.; RICAROD, F. (Orgs.). Povos indígenas no Brasil: 2001 - 2005. São Paulo: Instituto Socioambiental.

STAFFORD, J. (2016). Colonial Literature and the Native Author: indigeneity and empire. Gewerbestrasse: Palgrave Macmillan.

STANLEY, L. (2015). The Death of the Letter? Epistolary Intent, Letterness and the Many Ends of Letter-Writing. SAGE journals, v. 9, n. 2, p. 240-255.

XAVANTE; MEHINAKU (2000). Carta entregue ao então Presidente Fernando Henrique Cardoso. Disponível em: < http://brazil.indymedia.org/content/2004/01/272987.shtml $>$. Acesso em: 16 ago. 2016.

YANOMAMI. (2003). Yanomami do Demini dirigem-se ao novo governo. Carta enviada ao Presidente Luís Inácio Lula da Silva. Disponível em: < http://www.proyanomami.org.br/v0904/ index.asp? pag $=$ noticia\&id $=1442>$. Acesso em: 15 jul. 2017.

YANOMAMI. (2003). Carta dos Yanomami aos Presidenciáveis. Disponível em: < http://www. proyanomami.org.br/v0904/index.asp?pag =noticia\&id $=1389>$. Acesso em: 12 out. 2017.

Recebido: $1 / 10 / 2018$

Aceito: 19/10/2018 